\title{
Moisture and soil strength monitoring of a railway embankment remediated with wicking geotextile
}

\author{
Camila Alvarenga ${ }^{1}$, Parisa Haji Abdulrazagh ${ }^{1}$, and Michael T. Hendry ${ }^{1}$ \\ ${ }^{1}$ Faculty of Engineering - University of Alberta, Edmonton, Alberta, Canada
}

\begin{abstract}
A $45 \mathrm{~m}$ section of a railway embankment located at Fort Saskatchewan County in Alberta, Canada, was remediated as a part of the Canadian Pacific Railway's (CP) Grade Stabilization/Remediation Plan. The embankment materials were replaced while a $4.6 \mathrm{~m}$ wide reinforcing geotextile (Mirafi ${ }^{\circledR}$ RS580i) and a $7.3 \mathrm{~m}$ wide wicking geotextile (Mirafi ${ }^{\circledR} \mathrm{H} 2 \mathrm{Ri}$ ) were installed in the ballast and sub-ballast interface and between the subgrade and sub-ballast, respectively, aiming to address issues such as poor drainage and moisture retention. The studied site consists of an instrumented track including a remediated and an adjacent control section that provided the opportunity to measure volumetric water content (VWC) within the subballast and clayey subgrade at both configurations. The VWC variation with seasonal weather change is continuously monitored by nine moisture sensors, and an antecedent precipitation index (API) model was developed to evaluate the influence of precipitation events on the VWC in both sections and to interpret the impact of the in situ VWC on the unsaturated strength of the soil according to the soil-water characteristic curve (SWCC) results. An initial evaluation of the moisture-suction relationship has shown that the subgrade soil strength is improving within the remediated section; nonetheless, these trends are anticipated to be more consistent with long-term observation.
\end{abstract}

\section{Introduction}

Railways are essential for the transportation of goods and people throughout Canada, having an important role in the economy. It is, therefore, crucial to design these structures to maintain good conditions while keeping the maintenance work as short as possible. One of the main factors that affect the track performance is the drainage capability of the track, which should be related to the local climatic and soil conditions when designing a railway system (Indraratna et al. 2011 [9]; Li et al. 2002 [11]; Rushton and Ghataora 2014 [12]).

Water accumulation due to poor drainage is a common cause of track substructure problems, leading to a decrease in the serviceable lifespan of the track and an increase in maintenance costs. Several issues can be mentioned, such as pumping of fine-grained soils, track settlement, soil volume change, ballast degradation, frost heave/thaw softening and cess heave due to strength reduction (Indraratna et al.2011 [9]; Li et al. 2002 [11]).

The track drainage system can be divided into internal and external drainage, where internal drainage boosts the flow of water out of the track and external drainage prevents water from other sources to enter the railway ( $\mathrm{Li}$ et al. 2002 [11]). Indraratna et al. (2012) [9] mentioned that the use of geotextiles, when appropriately designed and installed, can be a cost-effective alternative to improve the drainage of railways.

Wang et al. (2016) [16] stated that Mirafi ${ }^{\circledR} \mathrm{H} 2 \mathrm{Ri}$ is capable of improving the lateral drainage of the embankment materials through the use of capillary action within its wicking fibres; therefore, reducing the moisture retention in the embankment materials and subgrade soils even under unsaturated conditions.

This study aimed to evaluate the impact of the inclusion of a wicking geotextile in a railway embankment in terms of the drainage properties and soil strength of the embankment materials. The investigation included the use of meteorological and moisture data in order to analyse the influence of precipitation events on both the moisture content and the strength of the subgrade.

\section{Materials and Methods}

\subsection{Site Description}

The research site is located at Fort Saskatchewan County in Alberta, Canada. The railway subgrade soil at the area is mostly composed of fine materials, and the track has presented clay pumping and settlement. These issues are believed to be related to poor drainage and water retention occurring within both the embankment and the subgrade. The site was divided into two sections, which include one unchanged and one remediated. At the remediated section, the embankment was excavated down to the subgrade; then, the section was reconstructed with clean ballast, sub-ballast and geotextiles as per Fig. 1. The length of the remediated site was $45 \mathrm{~m}$ (148 ft.). The

\footnotetext{
* Corresponding author: calvaren@ualberta.ca
} 
control section did not undergo any changes, except for the installation of the access pipes for moisture sensors.

This site made it possible to assess seasonal changes of moisture content within the subgrade at an area with known drainage issues, while also evaluating the effectiveness of the chosen remediation. Moisture sensors were used to collect data at the shoulders of the sub-ballast and the centreline of both the sub-ballast and subgrade layers. Unfortunately, it was not possible to compare remediations with and without the use of the wicking geotextile.

It was expected that the wicking geotextile would improve the lateral drainage of the track, showing lower moisture contents on the subgrade and embankment materials after precipitation events, thus leading to soil strength retention.

\subsection{Geotextiles}

The geotextiles installed at the remediated site are Mirafi ${ }^{\circledR}$ RS580i and Mirafi ${ }^{\circledR}$ H2Ri, shown as solid pink and green lines, respectively, in Fig. 1. The function of Mirafi ${ }^{\circledR}$ RS580i is soil reinforcement and confinement (Tencate Geosynthetics 2018 [15]), while Mirafi ${ }^{\circledR}$ H2Ri has wicking yarns woven in the textile, which are responsible for improving lateral drainage and reducing water accumulation (Wang et al. 2016 [16]). Mirafi ${ }^{\circledR}$ RS580i and Mirafi ${ }^{\circledR}$ H2Ri mechanical and hydraulic properties are detailed in Tencate Geosynthetics (2018) [15] and Tencate Geosynthetics (2015) [14], respectively.

\subsection{Site Instrumentation}

Soil moisture sensors capable of measuring bulk electrical conductivity, volumetric water content (VWC) and soil temperature were placed at both sections for the investigation. The five sensors installed at the control section were called "T sensors" and the five sensors installed at the remediated area are defined as "TG sensors". The location and depth of each sensor are shown in Table 1.

For the reconstruction of the remediated section, the pre-existing ballast and sub-ballast were excavated in the length of $45 \mathrm{~m}$ (148 ft). The sensors in the subgrade section were then installed in a trench, being backfilled afterward. The wicking geotextile was placed on the top of the subgrade, followed by the placement of the subballast, ballast and track panel. The sensors in the subgrade of the remediated section were placed during the reconstruction process to avoid damaging the geotextile. For the same reason, no access pipes were inserted (Figs. 2 and 3 ).

The sensors at the control site and the sub-ballast of the remediated section were installed after the placement of access pipes. Two data loggers were used, one for the control site and one for the remediated section.

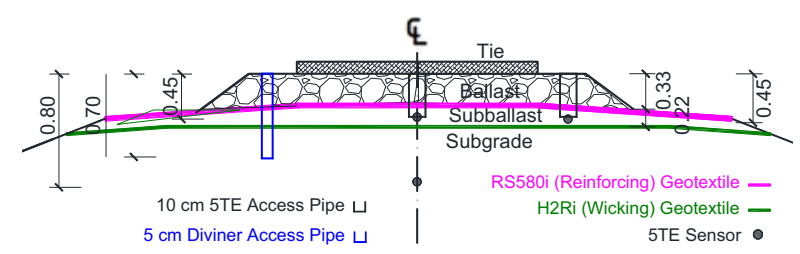

Fig. 1. Reinforcing (Mirafi ${ }^{\circledR}$ RS580i) and wicking (Mirafi ${ }^{\circledR}$ $\mathrm{H} 2 \mathrm{Ri}$ ) geotextiles location (dimensions in $\mathrm{m}$ ) (Alvarenga et al. $2020[1])$.

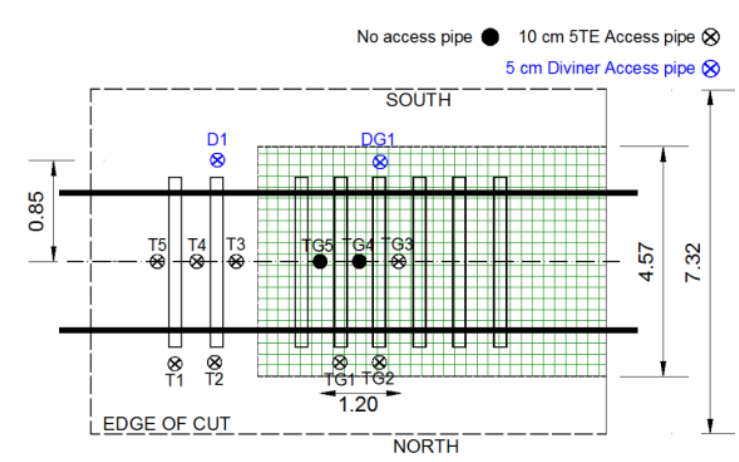

Fig. 2. Location of access pipes (dimensions in $\mathrm{m}$ ) (Alvarenga et al. 2020 [1]).

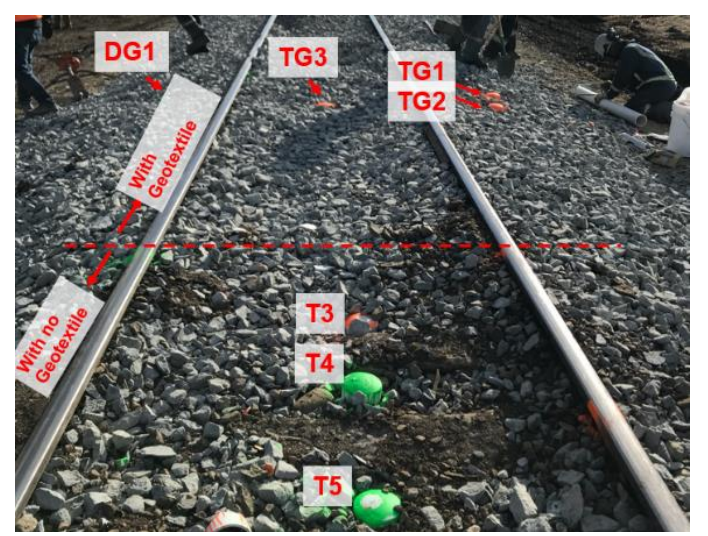

Fig. 3. Installed access pipes at the track (Alvarenga et al. 2020 [1]).

Table 1. Location of access pipes for moisture sensors.

\begin{tabular}{|c|c|c|c|c|}
\hline Sensor & $\begin{array}{l}\text { Depth } \\
\text { (m) }\end{array}$ & $\begin{array}{c}\text { Position at } \\
\text { Track }\end{array}$ & Section & Colour \\
\hline $\begin{array}{l}\text { TG1/ } \\
\text { TG2 }\end{array}$ & 0.45 & Shoulder & Remediated & Orange \\
\hline TG3 & 0.45 & Centreline & Remediated & Orange \\
\hline $\mathrm{TG}^{1}$ & 0.80 & Centreline & Remediated & - \\
\hline TG5 & 0.80 & Centreline & Remediated & - \\
\hline $\mathrm{T} 1 / \mathrm{T} 2$ & 0.45 & Centreline & Control & Green \\
\hline $\mathrm{T} 3$ & 0.45 & Shoulder & Control & Green \\
\hline $\mathrm{T} 4$ & 0.65 & Centreline & Control & Green \\
\hline T5 & 0.80 & Centreline & Control & Green \\
\hline D1 & 0.60 & Shoulder & Control & White \\
\hline DG1 & 0.70 & Shoulder & Remediated & White \\
\hline
\end{tabular}

1 Sensor did not work. 
The soil moisture sensors were connected to the dataloggers, which were set up to perform readings of soil temperature, bulk electrical conductivity and VWC at 12hour intervals.

\subsection{Meteorological Data}

Climate data was acquired in the ECCC (2020) [4] website, using measurements from one station that is located $6.06 \mathrm{~km}$ from the site. This station provided daily air temperature, rainfall, snowfall and total precipitation. Meteorological data from 2008-2018 was used (Figs. 4 and 5) to determine the historical trend of the region. Data from 2019-2020 was also collected for the analysis and comparison with the historical data. The 2019-2020 period showed higher precipitation than expected amid the summer as well as during the months of October and November. The temperatures during the study were similar to the 10 -year average.

The use of this data provided us important information, such as when snow accumulation is expected to occur and when spring thawing starts.

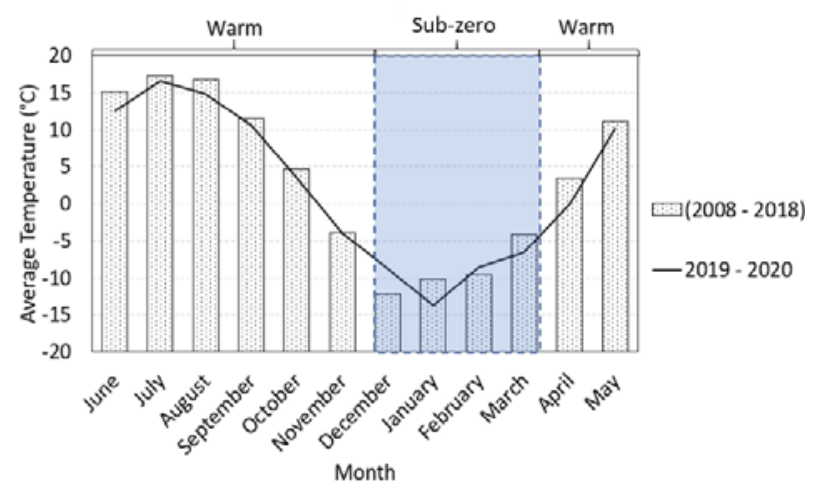

Fig. 4. 10-year average temperature (2008-2018), vs. recorded temperatures (2019-2020) (data from ECCC (2020) [4]).

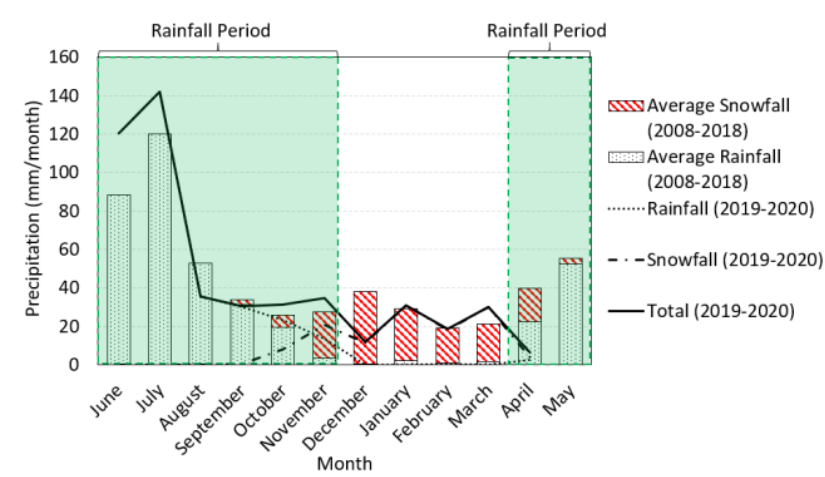

Fig. 5. 10-year average precipitation (2008- 2018) vs. recorded precipitation (2019 and 2020) (data from ECCC (2020) [4]).

\section{Material Characterization}

In order to understand the soil behaviour and to verify the applicability of the method presented, it was necessary to perform characterization tests. Sieve analysis, moisture content, specific gravity, and Atterberg limits tests were performed, with three tests being performed for each soil layer, except for the moisture content and particle size distribution (PSD) tests that had only one test performed per soil type due to the number of samples available.

Tests were performed for the materials of the two sections, except for the subgrade, which is the same for both. It was necessary to test the materials from the control section separately since the remediated section was renovated with clean materials. The materials of the control section are identified by "CS", and the remediated section materials are labelled with an "RS" throughout this paper.

Fig. 6 shows the particle size distribution for each soil tested. The ballast of the control section had some sand due to the presence of a transition zone between the ballast and sub-ballast layers, caused by traffic loading. However, the ballast and sub-ballast of both sections have shown less than $10 \%$ of fine content. The subgrade is composed of fine materials and presented approximately $50 \%$ of particles smaller than $0.075 \mathrm{~mm}$.

In order to check field moisture conditions, gravimetric moisture content tests were performed. The results for all soils are summarized in the column "GWC" of the table shown in Fig. 6. While the sub-ballast has shown a moisture content between 3 and $4 \%$ for both sections, the ballast of the remediated section ballast has shown a lower moisture content $(\sim 1 \%)$ than the control section (3\%), which could be attributed to the presence of sand in the ballast of the control section.

Soil water characteristic curves (SWCCs) define the relationship between the moisture content and matric suction, providing a function that is often used for the evaluation of unsaturated soil properties (Fredlund et al., 2012 [6]). These curves were, therefore, necessary to estimate the in-situ suction for the shear strength analysis of the soils found at the embankment, which are under unsaturated conditions.

The estimation of the SWCC curve for the subgrade material was done by applying the Zapata (1999) correlations due to time constraints (Fig. 7). The fitting parameters (i.e., $\mathrm{a}_{\mathrm{f}}, \mathrm{m}_{\mathrm{f}}, \mathrm{n}_{\mathrm{f}}$, and $\mathrm{h}_{\mathrm{r}}$ ) are estimated using PSD and Atterberg limits tests according to the following:

$$
\begin{gathered}
a_{f}=0.00364(w P I)^{3.35}+4(w P I)+11 \\
m_{f}=0.0514(w P I) \cdot 465+0.5 \\
n_{f}=m_{f}\left(-2.313(w P I)^{0.14}+5\right. \\
h_{r}=a_{f}\left(32.44 e^{0.0186(w P I)}\right)
\end{gathered}
$$

where $\mathrm{w}$ is the percent passing the No. 200 sieve and PI is the plasticity index of the soil. These fitting 


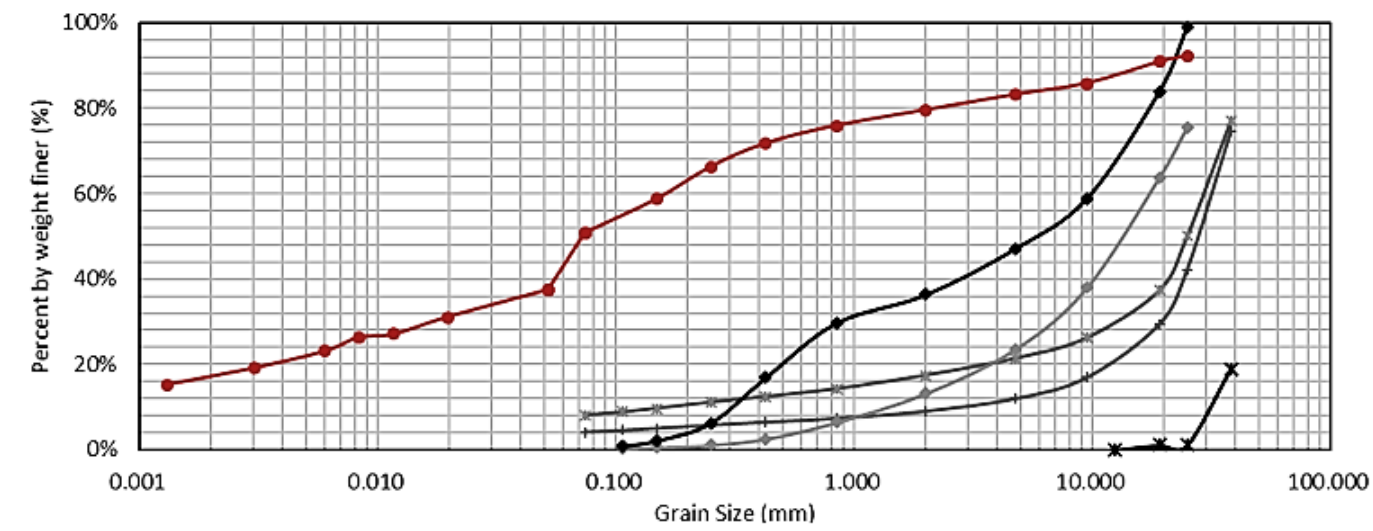

\begin{tabular}{|c|c|c|c|c|c|c|c|c|c|c|c|c|c|c|}
\hline Sample & Location & Symbol & $\begin{array}{c}\text { Depth } \\
(\mathrm{m}\rangle\end{array}$ & $\begin{array}{c}D_{10} \\
(\mathrm{~mm})\end{array}$ & $\begin{array}{c}\mathrm{D}_{3 \mathrm{c}} \\
(\mathrm{mm})\end{array}$ & $\begin{array}{c}\mathrm{D}_{\mathrm{EC}} \\
(\mathrm{mm})\end{array}$ & $\begin{array}{l}\text { Passing } \\
\# 200 \text { (w) }\end{array}$ & Sand & Gravel & GWC & LL & PL & $\mathrm{PI}$ & Gs \\
\hline Ballast top & Control & $\overline{1}$ & 0.25 & 3 & 19.7 & 31.8 & $4.1 \%$ & $3.9 \%$ & $92.0 \%$ & $2.3 \%$ & - & - & - & - \\
\hline Ballast bottom & Control & 4 & 0.33 & 0.17 & 12.5 & 29.4 & $8.1 \%$ & $9.3 \%$ & $82.6 \%$ & $3.7 \%$ & - & - & - & - \\
\hline Sub-ballast & Control & & 0.5 & 1.36 & 6.9 & 17.5 & $0.3 \%$ & $12.7 \%$ & $87.0 \%$ & $4.2 \%$ & - & - & - & 2.71 \\
\hline Ballast & Remediated & & 0.3 & 31.5 & - & - & $0 \%$ & $0.0 \%$ & $100.0 \%$ & $0.2 \%$ & - & - & - & - \\
\hline Sub-ballast & $\begin{array}{l}\text { Remediated } \\
\text { Remediated }\end{array}$ & & 0.5 & 0.31 & 0.87 & 10 & $0.1 \%$ & $35.6 \%$ & $63.5 \%$ & $3.6 \%$ & - & - & - & 2.68 \\
\hline Subgrade & and Control & & 0.8 & - & 0.017 & 0.165 & $50.1 \%$ & $28.7 \%$ & $20.5 \%$ & $20.6 \%$ & 40 & 19 & 21 & 2.73 \\
\hline
\end{tabular}

Fig. 6. Material characterization for railway embankment materials.

parameters were then processed using the Fredlund and Xing (1994) [6] equation:

$$
\begin{aligned}
& \theta(\psi)=C(\psi) \frac{\theta_{s}}{\left\{\ln \left[e+\left(\psi / a_{f}\right)^{n_{f}}\right]\right\}^{m_{f}}} \\
& C(\psi)=1-\left\{\frac{\ln [1+\psi / \psi r]}{\ln [1+1000000 / \psi r]}\right\}
\end{aligned}
$$

where $\theta$ is the VWC corresponding to a selected soil suction, $\theta_{\mathrm{s}}$ is the saturated VWC, $\psi$ is the suction, e is equal to $2.72, \mathrm{C}(\psi)$ is the correction factor defined by Eq. 6 and $\psi_{\mathrm{r}}$ is the suction at the residual value.

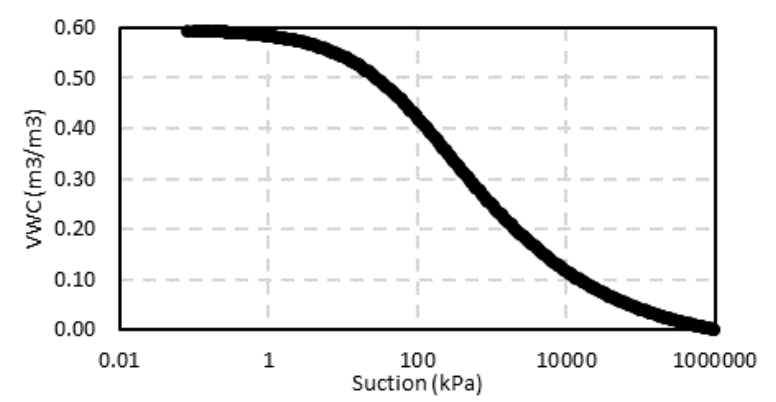

Fig. 7. Estimated SWCC for subgrade (Alvarenga et al. 2020 [1]).

\section{Results and Discussion}

\subsection{Sensors Performance}

The data from the moisture sensors were recorded at an interval of 12 hours between July 2019- October 2020. The sensors and the dataloggers were checked monthly to ensure they were properly working, and some issues were found.

One of the sensors, TG4, was possibly damaged during the reconstruction of the reinforced embankment and did not function. This sensor is inaccessible, as it was installed at a trench before the track reconstruction; therefore, it was not possible to replace it with a functioning sensor. Also, no data was collected between July 24, 2019, and September 19, 2019, for the control section due to datalogger malfunction.

The datalogger at the control section presented issues recording moisture values from $\mathrm{T} 1$ (installed at the subballast). Only a few readable measurements were done between May-August 2020.

One of the dataloggers also stopped recording values in September 2020, and due to this reason, the data analyzed in this paper goes from July 2019-September 2020.

\subsection{VWC Measurements}

The VWC fluctuations between 12-hour readings for all sensors were averaged daily due to important variations through the day when higher amounts of precipitation occurred. The period chosen for this analysis occurred between July 24, 2019 - November 8, 2019, and February 25-September 07, 2020 due to snow accumulation and freezing temperatures occurring between these intervals. All the information related to the remediated section and the control section in graphs is shown in red and black, respectively, as shown in Fig. 8.

The sub-ballast shoulder of the track (T1, T2, TG1 and TG2) have not shown a great difference between them regarding the influence of precipitation, presenting the same moisture trend after spring-thaw occurred. The remediated section kept higher VWC values throughout the entire study. This trend could be attributed to the release of water from the geotextile at the end of the track 

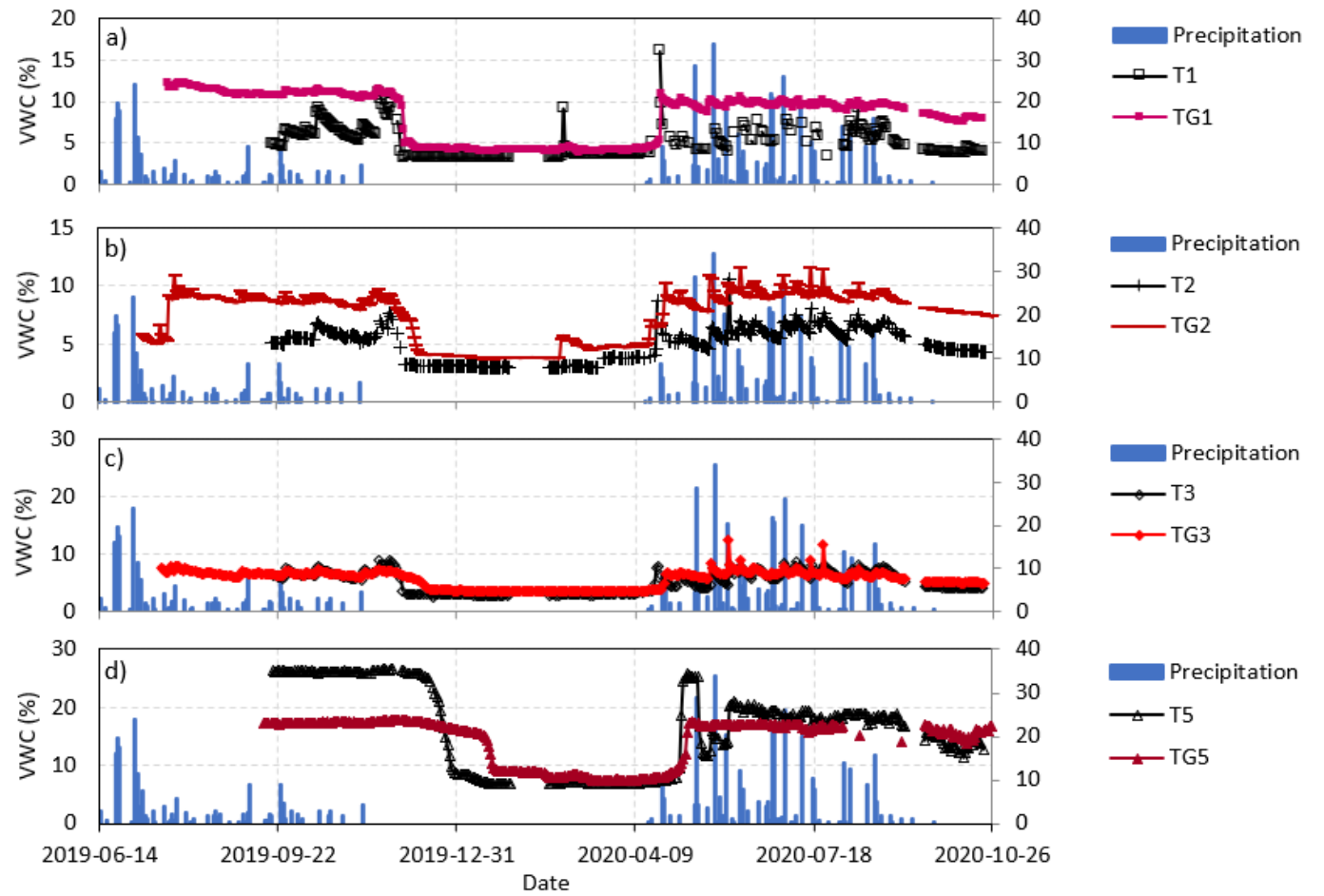

Fig. 8. VWC and precipitation recordings for a) and b) Sub-ballast shoulder, c) Sub-ballast centreline and d) Subgrade centreline.

shoulder; however, this interpretation must be treated with care.

The sub-ballast centreline sensors (T3 and TG3) have shown similar VWC for both sections, but the influence of precipitation appears to be more pronounced in the control section (Fig. 8). During times of higher precipitation and (consequently) moisture, the control section has shown to have VWC points reaching higher values than the remediated section, with a difference between 0.3 and $1 \%$. The sensor in the control section also had sharper changes in the VWC throughout the study.

The control section showed a higher VWC in the subgrade at all times throughout the study, except during the freezing period. The VWC values reached a peak on May 11, 2020, due to the spring-thaw season, and the control section seemed to be more influenced by the water released from the snow deposits. While the control section showed a VWC of $26 \%$, the remediated section reached only $17 \%$ after the snow thawing. An odd trend is seen for sensor T5 (Fig. 8(d)). While the moisture remained unchanged before the freezing period (around $26 \%$ ), the moisture varied greatly after the spring thaw. Initially, the same moisture was measured at the control section, which could be attributed to ice melting within the subgrade layer with the increase in temperatures.

By monitoring the soil behaviour through the springthaw and summer, factors such as the impact of the embankment reconstruction were ruled out. The soil has shown a very different behavior after spring-thaw occurred. It is important to remind that with a long-term analysis the trend seen would clarify how the geotextile behaves and whether the effects of its implementation are durable.

\subsection{API - SWE Model}

Soil properties, topography, vegetation, precipitation, evapotranspiration, temperature and wind speed influence the soil water content (Gwak and Kim, 2016 [8]). However, a system able to consider all those variables in the change of moisture would require complex computation models.

API is one of the simplest hydrological models used to estimate soil moisture. It calculates soil moisture using only the local precipitation, where the retrieved soil moisture product has the same temporal and spatial resolution as the input forcing precipitation product. (Bulut et al. 2019 [3])

The use of an API model allowed us to understand the interrelationship between precipitation and VWC at a daily scale by correlating the precipitation data from the weather stations and the VWC measurements obtained from the moisture sensors. The first API concept was introduced by Kohler and Linsley (1951) [10] and is defined as shown in Eq. 7.

$$
A P I_{t}=\sum_{t=0}^{d} P_{t} k^{t}
$$

where $P_{t}$ is the precipitation at day $t, k$ is the attenuation coefficient $(0<\mathrm{k}<1)$ and $\mathrm{t}$ refers to the time in days. The attenuation coefficient was estimated for each layer according to the best curve fitting value. These values are shown in Tables 2 and 3. The estimation of $\mathrm{k}$ requires computations; however, it is probably not justified as experience has shown that the factor is not 
critical (Kohler and Linsley 1951 [10]). The VWC data analysis went from July 23, 2019, to Sept 7, 2020.

Aiming to consider the influence of the snow on the API, a snow-water equivalent (SWE) model was used to convert the snowfall to precipitation values. The SWE model by Sturm et al. (2010) [13] is defined as:

$$
S W E=h_{s} \frac{\rho_{b}}{\rho_{w}}
$$

where $\rho_{b}$ is the snow density and $\rho_{\mathrm{w}}$ is the water density. As snow density changes throughout the cold period, Sturm et al. (2010) [13] defined the snow density at day $t$ as:

$$
\begin{aligned}
\rho_{b_{i}, D O Y_{i}}=\left(\rho_{\max }\right. & \left.-\rho_{0}\right)[1 \\
& -\exp \left(-k_{1} \times h_{i}\right. \\
& \left.\left.-k_{2} \times D O Y_{i}\right)\right]+\rho_{0}
\end{aligned}
$$

where $\mathrm{k}_{1}$ and $\mathrm{k}_{2}$ are densification parameters for depth and day of the year, respectively; $\rho_{\max }, \rho_{0}, \mathrm{k}_{1}$, and $\mathrm{k}_{2}$ vary with snow class (for prairies, $\rho_{\max }=0.5940, \rho_{0}=0.2332$, $\mathrm{k}_{1}=0.0016$ and $\mathrm{k}_{2}=0.0031$ ); and $\mathrm{i}$ indicates the $i$ th observation. For this equation, DOY runs from -92 (1 October) to +181 (30 June), excluding the number zero and the warmer period of the year.

The precipitation $P_{t}$ in Eq. 7 can then be defined as:

$$
P_{t}=R_{t}+\Delta S W E_{t}
$$

where $R_{t}$ and $\Delta S W E_{t}$ are the rainfall and the variation of the accumulated snow water equivalent for day t. A graphical interpretation was then performed in VWC vs. API for each sensor applying a power regression model for optimization, previously used by Blanchard et al. (1981)[2] (Fig. 9 and 10):

$$
\theta_{v(t)}=\alpha A P I_{t}^{\beta}
$$

where $\alpha$ and $\beta$ are fitting parameters (Tables 2 and 3 ), and $\theta_{\mathrm{v}(\mathrm{t})}$ is the estimated VWC for day t. Examples of the curve fitting performed to find the $\alpha$ and $\beta$ values are shown in Figs. 9 and 10. After finding the power regression curves corresponding to the VWC-API relationship for each sensor, these were used to estimate VWC according to daily API (Fig. 11(a)-11(d)). The Rsquared value between the estimated $\mathrm{VWC}$ and actual VWC stayed between 0.22 and 0.82 (Tables 2 and 3 ).

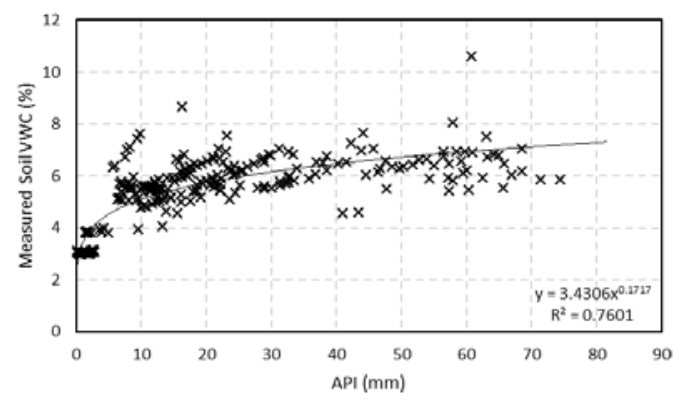

Fig. 9. Curve-fitting function for T2 sensor (control).

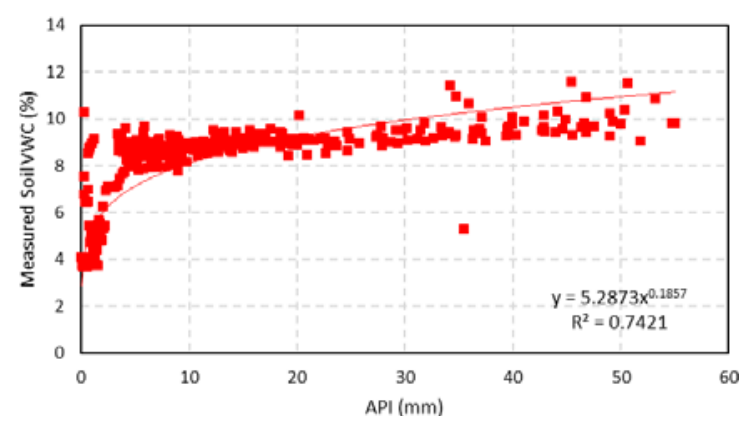

Fig. 10. Curve-fitting function for TG2 sensor (remediated).

The number of days affecting the VWC measurements, defined according to the best fit (Tables 2 and 3 ), have shown close results for both sections, staying within a difference of 2 days. While $\alpha$ values show the overall average value for the moisture, the values found for $\beta$ (Tables 2 and 3 ) express how the moisture is changing in each layer as precipitation occurs. The values found for $\beta$ indicate a less pronounced response to precipitation in the remediated section for the sub-ballast centreline and the subgrade. For example, the sensors at the sub-ballast centreline of this section displayed higher VWC than what is found at the control section $\left(\alpha_{\mathrm{TG} 3}=4.41 ; \alpha_{\mathrm{T} 3}=3.32\right.$, Tables 2 and 3), however, the VWC at the remediated section appears to be less influenced by precipitation as seen in Fig. 11(a) $\left(\beta_{\mathrm{TG} 3}=0.1532, \beta_{\mathrm{T} 3}=0.2102\right.$, Tables 2 and 3$)$.

The VWC recordings of the T5 sensor (subgrade, control) varied greatly after the freezing period, a trend not seen before the freezing period. Since the behaviour before and after the freezing period differ for this sensor, the model could not find a good fit for both periods altogether. For this reason, two fitting equations are fitted on T5 recordings, one before and one after the spring thaw of 2020. Before the spring thaw, T5 did not have great VWC changes, causing the relationship with API to be very weak $\left(R^{2}=0.24\right.$, Table 2$)$. This has changed after the spring thaw when $\mathrm{T} 5$ displayed considerable changes in the moisture content $\left(\mathrm{R}^{2}=0.82\right.$, Table 2$)$.

The subgrade of the control section had varying moisture contents, with the sharpest change occurring during the spring thaw period, while at the remediated section it maintained the same VWC values throughout the study. This behaviour at the remediated section is possibly due to the continuous moisture release by the wicking geotextile; this might explain the weak relationship between VWC and the API found.

Table 2. Fitting parameters for control section.

\begin{tabular}{cccccc}
\hline Sensor & Layer & $\mathrm{k}$ & $\begin{array}{c}\# \\
\text { Days }\end{array}$ & Fitting Curve & $\mathrm{R}^{2}$ \\
\hline $\mathrm{T} 1$ & Sub-ballast & 0.96 & 20 & $3.87 * \mathrm{API}_{\mathrm{t}}{ }^{0.148}$ & 0.52 \\
$\mathrm{~T} 2$ & Sub-ballast & 0.96 & 20 & $3.43 * \mathrm{API}_{\mathrm{t}}{ }^{0.1717}$ & 0.76 \\
$\mathrm{~T} 3$ & Sub-ballast & 0.96 & 15 & $3.32 * \mathrm{API}_{\mathrm{t}}{ }^{0.2102}$ & 0.70 \\
$\mathrm{~T} 4$ & Subgrade & 0.95 & 16 & $5.49^{*} \mathrm{API}_{\mathrm{t}}{ }^{0.2275}$ & 0.64 \\
$\mathrm{~T} 5^{1}$ & Subgrade & 0.95 & 16 & $26.53 * \mathrm{API}_{\mathrm{t}}{ }^{-0.005}$ & 0.24 \\
$\mathrm{~T}^{2}$ & Subgrade & 0.95 & 16 & $7.12 * \mathrm{API}_{\mathrm{t}}{ }^{0.2551}$ & 0.82 \\
\hline
\end{tabular}

${ }^{1}$ Before freezing period; ${ }^{2}$ After freezing period. 

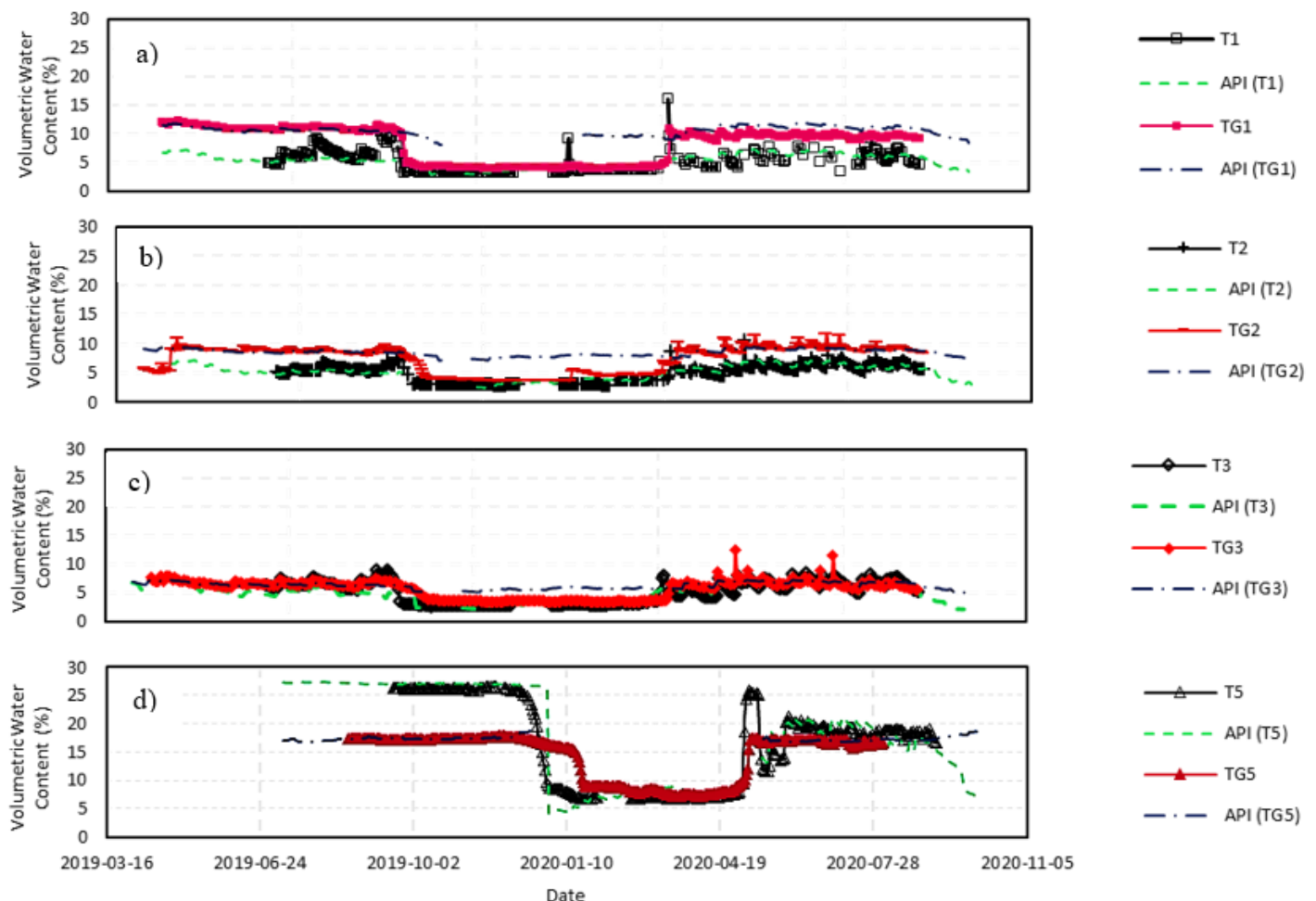

Fig. 11. VWC vs. API for a) and b) Sub-ballast shoulder, c) Sub-ballast centreline and d) Subgrade centreline.

Table 3. Fitting parameters for remediated section.

\begin{tabular}{cccccc}
\hline Sensor & Layer & $\mathrm{k}$ & $\begin{array}{c}\# \\
\text { Days }\end{array}$ & Fitting Curve & $\mathrm{R}^{2}$ \\
\hline TG1 & Sub-ballast & 0.92 & 20 & $6.02 * \mathrm{API}_{\mathrm{t}}{ }^{0.1866}$ & 0.51 \\
TG2 & Sub-ballast & 0.92 & 20 & $5.29 * \mathrm{API}_{\mathrm{t}}{ }^{0.1857}$ & 0.74 \\
TG3 & Sub-ballast & 0.92 & 13 & $4.41 * \mathrm{API}_{t}{ }^{0.1532}$ & 0.67 \\
TG5 & Subgrade & 0.95 & 15 & $17.53 * \mathrm{API}_{\mathrm{t}}{ }^{-0.009}$ & 0.22 \\
\hline
\end{tabular}

\subsection{Subgrade Suction Analysis}

The impact of both the wicking geotextile and VWC change on the strength of the subgrade by analysing the suction is observed in this section. The matric suction contribution to the soil shear strength in unsaturated soils can be visualized using Eq. 12, developed by Fredlund et al. (1978) [5]:

$$
\begin{aligned}
\tau=c^{\prime}+\left(\sigma-u_{w}\right) & \tan \varphi^{\prime} \\
& +\left(u_{a}-u_{w}\right) \tan \varphi^{b}
\end{aligned}
$$

where $\tau$ is the shear strength, $\mathrm{c}^{\prime}$ is the effective cohesion; $\sigma$ is the total normal stress, $\left(u_{a}-u_{w}\right)$ is the matric suction, $\mathrm{u}_{\mathrm{w}}$ is the pore-water pressure and $\varphi^{\prime}$ is the friction angle concerning changes in $\left(\sigma-\mathrm{u}_{\mathrm{w}}\right)$ when $\left(\mathrm{u}_{\mathrm{a}}-\right.$ $\mathrm{u}_{\mathrm{w}}$ ) is held constant; and $\varphi_{\mathrm{b}}$ is the friction angle concerning changes in $\left(\mathrm{u}_{\mathrm{a}}-\mathrm{u}_{\mathrm{w}}\right)$ when $\left(\sigma-\mathrm{u}_{\mathrm{w}}\right)$ is held constant.

In unsaturated conditions, the presence of higher suction values leads to an increase in the shear strength and a consequent improvement in the bearing capacity of the material. The remediated section has shown a lower VWC before the spring-thaw of 2020, which led to higher suctions throughout the period of the study. The remediated section has maintained suction values 1000 $2000 \mathrm{kPa}$ higher than the control section (Fig. 12), except during the sub-zero period. However, the sensors' measurements can be uncertain at this period as ice is present instead of water, therefore this information should be handled carefully.

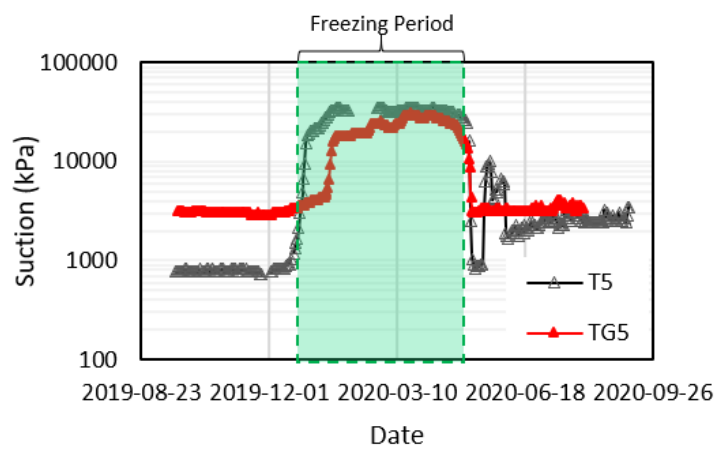

Fig. 12. Suction values for control (T5) and remediated section (TG5).

\section{Conclusions}

A comparison of the performance of the wicking geotextile to a common embankment was performed by instrumenting adjacent sections and analyzing the relationship of moisture content with precipitation. The preliminary API model considered rainfall as well as snowfall by using an SWE model which improved the accuracy of the model. The early results indicated that the sub-ballast shoulder is equally sensitive to precipitation according to the API model in both sections as suggested by the $\beta$-values. However, the sub-ballast centreline has shown less variation in its water content at the remediated section. 
The VWC presented a better relationship to precipitation for the subgrade in the control section after spring-thaw, despite not presenting great changes in its levels during the summer of 2019, indicating to be influenced by snowmelt and precipitation, while the remediated section did not have significant changes in moisture, except for the freezing period, when the water present at the soil freezes.

The lower VWC found at the subgrade of the remediated section leads to higher suction values and consequently higher soil strength throughout the "warm" period of the year and lower suction values during the freezing period. However, the changes in VWC during the cold period could be due to water freezing within the soil and may not be detected by the moisture sensors.

The behaviour seen indicates that the wicking geotextile can be improving the drainage of the track, since no significant moisture changes were seen throughout the study at the remediated section, even during the spring thaw, while the control section has shown great variance in VWC. These changes in VWC also affect the soil strength. The subgrade has shown a higher soil suction at the remediated section during the study, which may lead to higher shear strength values. Long-term analysis is necessary to confirm the effects of the geotextile on the track performance throughout the maintenance lifespan. Another alternative to this study is the use of the highest moisture value found daily instead of the average of the VWC measurements to implement the API model, as well as the use of cluster analysis for a longer-term analysis to group similar observations as the number of data points increases.

\section{Acknowledgement}

This research was made possible through the support of the Railway Ground Hazard Research Program, funded in part by the Natural Sciences and Engineering Research Council of Canada (NSERC), Canadian Pacific and Canadian National Railway.

Special thanks to Canadian Pacific Railway for providing the site and support for this research project.

\section{References}

1. C. Alvarenga, P. Haji Abdulzaragh, M. T. Hendry (2020). Monitoring of the change of moisture beneath a railway embankment and the effectiveness of a wicking geotextile. Proceedings of the $73^{\text {rd }}$ CGS Conference, GeoVirtual 2020, Calgary, September 14, 2020.

2. B. J. Blanchard, M. J. Mcfarland, M. J., T. J. Schmugge, \& E. Rhoades (1981). Estimation of Soil Moisture with API Algorithms and Microwave Emission. Journal of the American Water Resources Association, 17(5), 767-774. DOI: 10.1111/j.1752-1688.1981.tb01296.

3. B. Bulut, M. Yilmaz, M. H. Afshar, Ü. Şorman, I. Yucel, M. Cosh, \& O. Şimşek (2019). Evaluation of Remotely Sensed and Model-Based Soil Moisture Products According to Different Soil Type,
Vegetation Cover and Climate Regime Using Station-Based Observations over Turkey. Remote Sensing 11. DOI: $10.3390 / r s 11161875$

4. Environment and Climate Change Canada (ECCC) (2020). Historical Data: 2008-2018. Accessed April 09, 2020, from https://climate.weather.gc.ca/historical data/search historic_data_e.html.

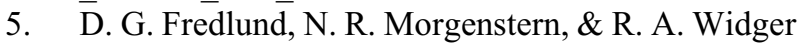
(1978). The shear strength of unsaturated soils. Accessed April 17, 2020, from https://www.nrcresearchprdoi/10.1139/t78-029.

6. D. G. Fredlund, H. Rahardjo \& M. D. Fredlund (2012). Unsaturated Soil Mechanics in Engineering Practice. New York, NY: John Wiley \& Sons Inc. doi: 10.1002/9781118280492.

7. D. G. Fredlund, A. Xing (1994). Equations for the soil-water characteristic curve. Canadian Geotechnical Journal, 31(4), 521-532.

8. Y. Gwak \& S. Kim. (2016). Factors affecting soil moisture spatial variability for a humid forest hillslope. Accessed April 20, 2020, from https://onlinelibrary.wiley.com/doi/abs/10.1002/hy p.11039.

9. B. Indraratna, W. Salim, \& C. Rujikiatkamjorn (2011). Advanced Rail Geotechnology: Ballasted Track (1st ed.). Boca Raton: CRC Press/Taylor \& Francis Group. DOI: 10.1201/b10861.

10. M. A. Kohler \& R. K. Linsley (1951). Predicting the Runoff from Storm Rainfall. Accessed April 18, 2020 ,

https://www.nrc.gov/docs/ML0819/ML081900279 .pdf.

11. D. Li, J. Hyslip, T. Sussmann \& S. Chrismer. (2002). Railway Geotechnics (1st ed.). London: CRC Press. DOI: 10.1201/b18982.

12. K. R. Rushton \& G. Ghataora (2014). Design for efficient drainage of railway track foundations. In Proceedings of the Institution of Civil EngineersTransport (Vol. 167, No. 1, pp. 3-14). Thomas Telford Ltd.

13. M. Sturm, B. Taras, G. E. Liston, C. Derksen, T. Jonas \& J. Lea (2010). Estimating Snow Water Equivalent Using Snow Depth Data and Climate Classes. Journal of Hydrometeorology, 11(6), 1380-1394. DOI: $10.1175 / 2010 j h m 1202.1$

14. Tencate Geosynthetics (2015). Mirafi ${ }^{\circledR} H 2 R i$ Woven Geosynthetic for improved Soil Stabilization and Base Course Reinforcement through Continuous Moisture Management. Accessed April 30, 2019, https://www.tencategeo.us/enus/products/woven-geotextiles/mirafi-h2ri.

15. Tencate Geosynthetics (2018). Mirafi ${ }^{\circledR}$ RS580i. Accessed April 30, 2019, https://www.tencategeo.us/en-us/products/wovengeotextiles/mirafi-rsi-series.

16. F. Wang, J. Han, X. Zhang \& J. Guo (2017). Laboratory tests to evaluate effectiveness of wicking geotextile in soil moisture reduction. Geotextiles and Geomembranes, 45(1), 8-13. DOI: 10.1016/j.geotexmem.2016.08.002. 